\title{
Very Low Prenatal Exposure to Lead and Mental Development of Children in Infancy and Early Childhood
}

\author{
Krakow Prospective Cohort Study
}

\author{
Wieslaw Jedrychowski ${ }^{a}$ Frederica P. Perera ${ }^{c}$ Jeffery Jankowski ${ }^{d}$ \\ Dorota Mrozek-Budzyn ${ }^{a} \quad$ Elzbieta Mroz $^{\mathrm{a}} \quad$ Elzbieta Flak $^{\mathrm{a}}$ Susan Edwards ${ }^{\mathrm{c}}$ \\ Anita Skarupa ${ }^{a}$ Ilona Lisowska-Miszczyk ${ }^{b}$ \\ ${ }^{\mathrm{a}}$ Epidemiology and Preventive Medicine and ${ }^{\mathrm{b}}$ Obstetrics and Gynecology-Neonatology Clinic, Medical College, \\ Jagiellonian University, Krakow, Poland; ' Columbia Center for Children's Environmental Health, Mailman School \\ Public Health, Columbia University, and d Department of Pediatrics, Albert Einstein College of Medicine, \\ Yeshiva University, New York, N.Y., USA
}

\section{Key Words}

Prenatal lead exposure $\cdot$ Infant cognitive functioning •

Infant psychomotor functioning $\cdot$ Prospective cohort study

\begin{abstract}
Background: The primary purpose of the study was to establish a possible association between very low levels of prenatal exposure to lead and mental development of children at 12, 24 and 36 months of age. Methods: The study sample consisted of 444 children born to mothers who attended ambulatory prenatal clinics in Krakow inner city in the first and second trimesters of pregnancy. We assessed exposure to lead by the cord blood lead measurements, and mental development in infancy and early childhood using the Bayley Mental Development Index (MDI). The relationship between prenatal lead exposure and MDI scores at each followup period was evaluated with linear multivariate regression. To test the overall effect of maternal exposure to lead during pregnancy on the Bayley test scores at 12, 24 and 36 months of age, we used the generalized estimating equations (GEE) longitudinal panel model as well. Results: The median lead
\end{abstract}

level in cord blood was $1.23 \mu \mathrm{g} / \mathrm{dl}$, in the range of $0.44-6.90$ $\mu \mathrm{g} / \mathrm{dl}$. An adverse effect of prenatal lead exposure (logtransformed lead concentrations) on MDI scores at 12 months of age was of border significance $(\beta=-5.42,95 \% \mathrm{Cl}$ : -11.19 to 0.35). Subsequent testing of children at 24 months of age showed a significant inverse association of mental function and lead exposure ( $\beta=-7.65,95 \% \mathrm{Cl}:-14.68$ to -0.62$)$. A significant deficit in cognitive function due to prenatal lead exposure was also confirmed at 36 months of age $(\beta=-6.72$, $95 \% \mathrm{Cl}:-12.5$ to -0.89$)$. The GEE panel model showed that the average deficit in the cognitive development attributable to lead exposure over 3 years was also significant $(\beta=$ $-6.62,95 \% \mathrm{Cl}:-1.52$ to -1.72$)$. Mental function scores of girls were better than boys, and the effect of maternal education remained strongly significant in relation to mental function of 3-year-olds. Conclusion: The results of the study demonstrate that the neurotoxic impact of very low levels of prenatal lead exposure (below $5 \mu \mathrm{g} / \mathrm{dl}$ ) may occur in infants and very young children, and suggest a revision of established health guidelines for prenatal lead exposure criteria.

Copyright ๑ 2009 S. Karger AG, Basel

Wieslaw Jedrychowski, MD, PhD

Chair of Epidemiology and Preventive Medicine

Jagiellonian University Medical College

7, Kopernika Street, PL-31008 Krakow (Poland)

Tel. +48 1242310 03, Fax +48 1242287 95, E-Mail myjedryc@cyf-kr.edu.pl 


\section{Introduction}

Lead toxicity has been known for over 2,000 years, and is the most common and serious environmental hazard affecting not only adults, but children as well. For 2 decades, it has been known that in utero exposure to lead during the early stages of brain development is among the exogenous factors affecting neurobehavioral development of children $[1,2]$. The effect is due to the fact that humans begin to accumulate lead in their bodies during prenatal development. Because the fetal and infant brains are in a state of rapid growth, impairment of later cognitive function may result from even minor environmental toxic exposure. Since the placenta is not an effective biological barrier, pregnant women represent the group at increased risk because of maternal exposure of the fetus to lead [3-6].

The studies conducted earlier provided solid evidence that prenatal exposure to low-level environmental lead may have demonstrable effects on later cognitive and behavioral development of children [5, 7-14]. Although definite thresholds for various low-level lead-related health outcomes have not been established as yet, it has been suggested that the range of $5-10 \mu \mathrm{g} / \mathrm{dl}$ of lead in the blood of children or pregnant women may be acceptable. However, in the opinion of some investigators, further studies on the effect of blood lead in the range below $5 \mu \mathrm{g} / \mathrm{dl}$ are needed to better define the risk and to find more accurate tools to measure the smaller health outcomes $[15,16]$. To assess the developmental effects at very low lead exposure levels, more evidence is needed from cohort studies on neurocognitive deficits, especially from areas with relatively low community lead exposure.

Our primary purpose in the study was to establish a possible association between very-low-level prenatal exposure to lead and mental development of children at 12 , 24 and 36 months of age. The accumulated lead dose in infants over the pregnancy period was measured by the cord blood concentration of lead, and the Bayley Mental Development Index (MDI) was used to assess mental development in infancy and early childhood.

\section{Material and Methods}

The cohort originally consisted of 505 infants who were born at 33-43 weeks of gestation between January 2001 and February 2004 to mothers participating in an ongoing prospective cohort study. The material under analysis included 444 infants who completed the Bayley test upon entry to the study. The design of this cohort prospective study and the selection of the population have been described previously [17]. Women attending ambulatory prenatal clinics in the first and second trimesters of pregnancy were eligible for the study. The enrollment included only nonsmoking women with singleton pregnancies between the ages of 18 and 35 years, and who were free from chronic diseases such as diabetes and hypertension. Upon enrollment, a detailed questionnaire was administered to each subject to elicit information on demographic data, date of the last menstrual period, and medical and reproductive history. Environmental tobacco smoke (ETS) in pregnancy was recorded during standardized interviews with women performed by trained interviewers at the second and third trimesters of pregnancy. Exposure was estimated using a series of questions on the average number of cigarettes smoked at home or at work in the presence of women over the second and the third trimester of pregnancy.

\section{Blood Sample Collection and Analysis}

A cord blood sample (30-35 ml) was drawn into a Vacutainer tube that had been treated with ethylenediaminetetraacetate (EDTA). The tubes were inverted several times to mix the EDTA and the blood to prevent coagulation. Within $8 \mathrm{~h}$ of blood collection, the blood samples were transported to the clinical biochemistry laboratory at the University Hospital in Krakow for processing and storage. Packed red blood cells and plasma samples were separated and stored in liquid nitrogen in the laboratory prior to shipment to Columbia University. From Columbia University, portions of samples were then sent to the Centers for Disease Control for chemical analysis. Blood samples for lead analysis were refrigerated without any processing. Whole blood lead concentrations were determined using inductively coupled plasma mass spectrometry CLIA'88 method 'blood lead cadmium mercury ICPMS-ITB001A'. This multi-element analytical technique is based on quadrupole ICP-MS technology [18].

Mental Developmental Testing

The Bayley Scales of Infant Development second edition (BSID-II) includes a mental scale, the MDI [19]. The BSID-II results are based on the assessment of 178 standardized activities.

The number and sequence of these activities are chosen for each age group. The MDI assesses habituation, problem solving, early number concepts, generalization, classification, memory, vocalization, language and social skills.

The test results fall into 1 of 4 categories: (1) accelerated performance (equal or greater than a score of 115); (2) within normal limits (85-114); (3) mildly delayed performance (70-84); (4) significantly delayed performance $(\leq 69)$. For the purpose of the statistical analysis, the first 2 categories ( 1 and 2 ) were combined into 1 group (the normal performance), and the other 2 groups ( 3 and 4) were treated as the group with the delayed performance. The BSID-II test was administered to children within 4 weeks of the target age at the Department of Epidemiology and Preventive Medicine by 5 trained examiners who were unaware of the child's exposure. Interpretation of the Bayley test was based on the detailed instruction manual for evaluators [19]. Standardization of mental performance scoring was done in the course of team practice sessions with the team leader (I.L.-M.), who was trained at Columbia University, with follow-up surveillance of the assessors by J.J. from the Jeshiva University in New York.

\section{Statistical Data Analysis}

In the descriptive analysis, the distribution of various parameters related to women and newborns under study reflected by 
Table 1. Characteristics of the study subjects by lead exposure level

\begin{tabular}{|c|c|c|c|c|}
\hline \multirow[t]{2}{*}{ Variables } & \multirow{2}{*}{$\begin{array}{l}\text { Total } \\
(\mathrm{n}=444)\end{array}$} & \multicolumn{3}{|c|}{ Lead (cord blood) exposure level } \\
\hline & & $\begin{array}{l}\text { low exposure } \\
(\leq 1.23 \mu \mathrm{g} / \mathrm{dl} \\
\mathrm{n}=224)\end{array}$ & $\begin{array}{l}\text { high exposure } \\
(>1.23 \mu \mathrm{g} / \mathrm{dl} \\
\mathrm{n}=220)\end{array}$ & $\begin{array}{l}\text { geometric } \\
\text { mean, } \mu \mathrm{g} / \mathrm{dl}\end{array}$ \\
\hline \multicolumn{5}{|l|}{ Maternal education } \\
\hline Elementary & $42(9.5)$ & $17(7.6)$ & $25(11.4)$ & 1.42 \\
\hline Medium or high school & $110(24.8)$ & $48(21.4)$ & $62(28.2)$ & 1.34 \\
\hline University degree & $292(65.8)$ & $159(71.0)$ & $133(60.5)$ & 1.25 \\
\hline \multicolumn{5}{|l|}{ Infant characteristics } \\
\hline \multicolumn{5}{|l|}{ Gender } \\
\hline Boys & $225(50.7)$ & $115(51.3)$ & $110(50.0)$ & 1.30 \\
\hline Girls & $219(49.3)$ & $109(48.7)$ & $110(50.0)$ & 1.28 \\
\hline \multicolumn{5}{|l|}{ Birth order } \\
\hline 1 & $280(63.1)$ & $130(58.0)$ & $150(68.2)$ & 1.34 \\
\hline$\geq 2$ & $164(36.9)$ & $94(42.0)$ & $70(31.8)$ & 1.21 \\
\hline \multicolumn{5}{|l|}{ Prenatal exposure } \\
\hline \multicolumn{5}{|l|}{ ETS, $\mathrm{n}$} \\
\hline 0 cigarettes/day & $326(73.4)$ & $172(76.8)$ & $154(70.0)$ & 1.27 \\
\hline $1-10$ cigarettes/day & $97(21.8)$ & $43(19.2)$ & $54(24.5)$ & 1.32 \\
\hline$>10$ cigarettes/day & $21(4.7)$ & $9(4.0)$ & $12(5.5)$ & 1.51 \\
\hline MDI score at 12 months & $101.1 \pm 10.34$ & $101.7 \pm 10.04$ & $100.4 \pm 10.63$ & $\mathrm{p}=0.2162^{1}$ \\
\hline MDI score at 24 months & $101.2 \pm 13.00$ & $102.8 \pm 12.33$ & $99.5 \pm 13.50$ & $\mathrm{p}=0.0100^{1}$ \\
\hline Missing data & 26 & 11 & 15 & \\
\hline MDI score at 36 months & $103.1 \pm 10.26$ & $104.3 \pm 10.18$ & $101.8 \pm 10.21$ & \\
\hline Missing data & 58 & 29 & 29 & $\mathrm{p}=0.0166^{1}$ \\
\hline
\end{tabular}

MIDI scores presented as means \pm SD. Figures in parentheses are percentages.

${ }^{1} \mathrm{p}$ values for the differences between mean mental scores across the exposure groups.

lead exposure level has been considered. $\chi^{2}$ statistics (nominal variables) and ANOVA (numerical variables) were used to test differences between subgroups with low and higher lead exposure. The relationship between the lead in cord blood and MDI scores was evaluated with linear multivariate regression. In order to assess the average effect of maternal exposure to lead during pregnancy on the Bayley scale measured at 12, 24 and 36 months of child's age, the generalized estimating equations (GEE) model was applied [20].

GEE utilizes data of all respondents, including those with incomplete protocols, and permits simultaneous modeling of the relationship (regression) of specific risk factors with BSID-II score and all 3 measurements over the follow-up.

GEE estimates regression coefficients taking into account the correlation between scores at ages 12, 24 and 36 months. The described models computed regression coefficients of dependent variable (BSID-II performance scores) on the main predictor variable (cord blood lead level) and potential modifiers (maternal education, birth order, gender of child and ETS). Statistical analyses were performed with Stata software version 10 for Windows.

\section{Results}

Table 1 presents characteristics of the infants under study by blood lead level dichotomized by its median concentration (median $1.23 \mu \mathrm{g} / \mathrm{dl}$ ). The maternal education and the MDI scores were significantly lower in subjects from the higher exposure group. The overall geometric mean lead level in cord blood was $1.29 \mu \mathrm{g} / \mathrm{dl}$ (95\% CI: $1.24-1.34$ ) with a range of $0.44-6.90 \mu \mathrm{g} / \mathrm{dl}$. In total, about $90 \%$ of newborns had cord blood lead concentrations equal or below $5 \mu \mathrm{g} / \mathrm{dl}$ (fig. 1). We found the cord blood lead level significantly higher in the children with poorer performances at study entry (table 2 ).

BSID-II scores measured in the 3 follow-up time points cor related significantly with each other. The correlation coefficient between MDI scores measured at 12 months and 24 months was 0.38 (95\% CI: 0.30-0.46), and between MDI scores at 24 and 36 months this was 0.60 (95\% CI: $0.54-0.66)$. The cognitive performance of 


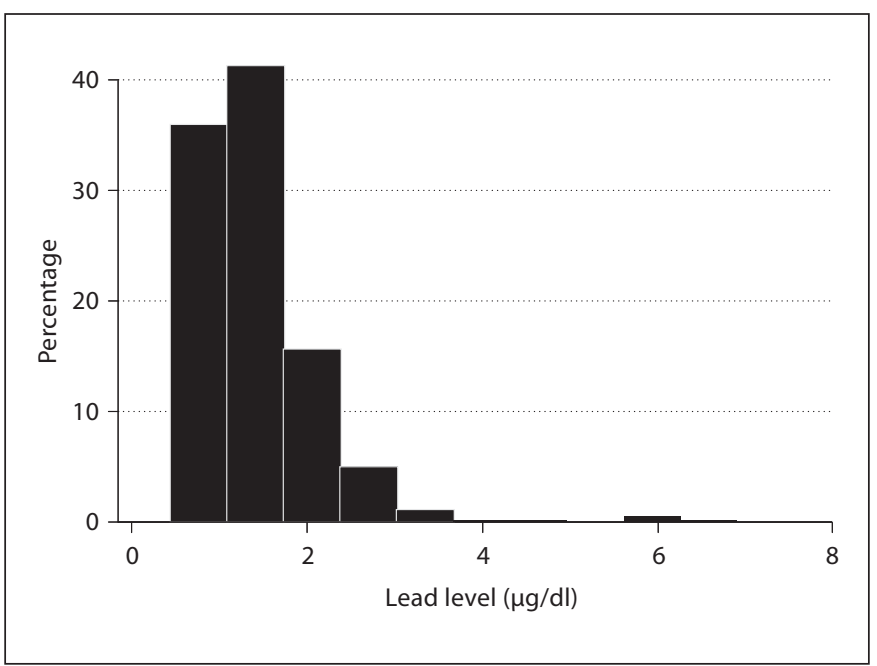

Fig. 1. Histogram of cord blood lead concentrations.

children measured by MDI scores over the 3-year follow-up increased with age. There were $6.3 \%$ of children with delayed cognitive functions at 12 months of age, and this proportion decreased to $4.7 \%$ by the age of 36 months.

Cross-tabulation of MDI scores by cord blood lead level (categorized by the quintiles of lead distribution) in the total study sample showed that the MDI score differed significantly across the exposure groups (table 3 ). The relationship between MDI scores measured over the followup and the cord blood lead level (log transformed) has been presented in figure 2 . In general, children with better maternal education had slightly higher MDI scores across exposure categories than those with lower maternal education (table 4).

Table 5 shows the adjusted effects of prenatal lead exposure (expressed in log-transformed units) on cognitive function (MDI) estimated in the linear multiple regression models at each follow-up time point. In the statistical models, the effects were adjusted for potential confounders (maternal education, parity, gender of child and prenatal ETS exposure). An adverse effect of prenatal lead exposure on MDI score at 12 months of age was of border significance ( $\beta=-5.42$; 95\% CI: -11.19 to 0.35 ). Subsequent testing of children at 24 months of age showed the significant inverse association of mental function and lead exposure ( $\beta=-7.65$; 95\% CI: -14.68 to -0.62$)$. The significant deficit in cognitive function due to prenatal lead exposure has also been confirmed at 36 months of age ( $\beta=-6.72$; $95 \% \mathrm{CI}:-12.55$ to -0.89$)$. In the follow-up
Table 2. Mean cord blood lead level by the BSID-II categories of children upon study entry (age of 12 months)

\begin{tabular}{ll}
\hline BSID-II categories & $\begin{array}{l}\text { Mean blood } \\
\text { lead level }\end{array}$ \\
\hline 1 accelerated performance & $1.3 \pm 0.54$ \\
2 within normal limits & $1.4 \pm 0.73$ \\
3 mildly delayed performance & $1.6 \pm 0.64$ \\
4 significantly delayed performance & $2.4 \pm 0.42$ \\
\hline
\end{tabular}

ANOVA for differences in cord blood lead levels between BSID-II categories: $\mathrm{F}=2.68$, d.f. $=3, \mathrm{p}=0.047$.

Table 3. Cross-tabulation of MDI scores by cord blood lead levels (categorized by the quintiles of lead distribution) in the total study sample

\begin{tabular}{|c|c|c|c|}
\hline $\begin{array}{l}\text { Cord blood lead } \\
\text { level }(\mu \mathrm{g} / \mathrm{dl})\end{array}$ & $\begin{array}{l}\text { MDI score } \\
(\text { means } \pm \mathrm{SD})\end{array}$ & $\mathrm{n}$ & $\begin{array}{l}\text { ANOVA and } \\
\mathrm{z} \text { test for trend }\end{array}$ \\
\hline \multicolumn{4}{|l|}{ MDI (12 months) } \\
\hline$\leq 0.91$ & $102.9 \pm 10.5$ & 88 & \multirow{6}{*}{$\begin{array}{l}F=1.62 \\
p=0.169 \\
z \text { for trend }=-1.61 \\
p=0.108\end{array}$} \\
\hline $0.92-1.11$ & $100.5 \pm 9.8$ & 91 & \\
\hline $1.12-1.39$ & $101.9 \pm 9.4$ & 90 & \\
\hline $1.40-1.81$ & $100.9 \pm 9.9$ & 87 & \\
\hline$>1.81$ & $99.2 \pm 11.9$ & 87 & \\
\hline Total & $101.1 \pm 10.4$ & 443 & \\
\hline \multicolumn{4}{|l|}{ MDI (24 months) } \\
\hline$\leq 0.91$ & $103.5 \pm 11.4$ & 83 & \multirow{6}{*}{$\begin{array}{l}F=2.98 \\
p=0.019 \\
z \text { for trend }=-1.96 \\
p=0.050\end{array}$} \\
\hline $0.92-1.11$ & $101.8 \pm 13.4$ & 88 & \\
\hline $1.12-1.39$ & $102.1 \pm 11.8$ & 84 & \\
\hline $1.40-1.81$ & $97.0 \pm 14.4$ & 82 & \\
\hline$>1.81$ & $101.4 \pm 13.1$ & 80 & \\
\hline Total & $101.2 \pm 13.0$ & 417 & \\
\hline \multicolumn{4}{|l|}{ MDI (36 months) } \\
\hline$\leq 0.91$ & $105.4 \pm 9.1$ & 73 & \multirow{6}{*}{$\begin{array}{l}F=2.56 \\
p=0.038 \\
z \text { for trend }=-2.56 \\
p=0.015\end{array}$} \\
\hline $0.92-1.11$ & $104.2 \pm 11.6$ & 82 & \\
\hline $1.12-1.39$ & $102.1 \pm 9.2$ & 79 & \\
\hline $1.40-1.81$ & $100.5 \pm 10.2$ & 75 & \\
\hline$>1.81$ & $103.2 \pm 10.5$ & 77 & \\
\hline Total & $103.1 \pm 10.3$ & 386 & \\
\hline
\end{tabular}

examinations, girls showed better cognitive ability than boys. While maternal education was found to have a positive impact on the child's mental function in successive testing, there were negative impacts of prenatal ETS on MDI scores at 24 months $(\beta=-0.31 ; 95 \%$ CI: -0.61 to $-0.018)$ and at 36 months $(\beta=-0.24 ; 95 \%$ CI: -0.47 to $-0.003)$. 
Table 4. Mean mental scores (unadjusted) achieved by children over the follow-up tabulated by the cord blood level (in quantiles) and maternal educational level

\begin{tabular}{|c|c|c|c|c|c|}
\hline & \multicolumn{5}{|c|}{ Cord blood lead level ( $\mu \mathrm{g} / \mathrm{dl})$} \\
\hline & $\leq 0.91$ & $0.92-1.11$ & $1.12-1.39$ & $1.40-1.81$ & $>1.81$ \\
\hline \multicolumn{6}{|c|}{ Maternal education } \\
\hline \multicolumn{6}{|c|}{ Lower level $^{1}$} \\
\hline $\begin{array}{l}\text { Number of } \\
\text { observations }\end{array}$ & 26 & 29 & 29 & 35 & 40 \\
\hline $\begin{array}{l}\text { MDI (12 } \\
\text { months) }\end{array}$ & 99.0 & 101.4 & 100.7 & 100.1 & 96.7 \\
\hline $\begin{array}{l}\text { MDI (24 } \\
\text { months) }\end{array}$ & 100.0 & 99.4 & 97.6 & 92.8 & 99.7 \\
\hline $\begin{array}{l}\text { MDI (36 } \\
\text { months) }\end{array}$ & 100.6 & 98.9 & 99.6 & 97.7 & 101.9 \\
\hline \multicolumn{6}{|l|}{ Higher level $^{2}$} \\
\hline $\begin{array}{l}\text { Number of } \\
\text { observations }\end{array}$ & 65 & 64 & 65 & 55 & 51 \\
\hline $\begin{array}{l}\text { MDI (12 } \\
\text { months) }\end{array}$ & 104.4 & 100.2 & 102.4 & 101.3 & 101.0 \\
\hline $\begin{array}{l}\text { MDI (24 } \\
\text { months) }\end{array}$ & 104.9 & 102.8 & 104.3 & 99.7 & 102.6 \\
\hline $\begin{array}{l}\text { MDI (36 } \\
\text { months) }\end{array}$ & 107.6 & 106.5 & 103.5 & 102.0 & 104.1 \\
\hline
\end{tabular}

Table 6 demonstrates the association between lead cord blood level (log transformed) and cognitive function estimated by the GEE model. The results obtained confirmed a significant average deficit in the cognitive development attributable to lead exposure over 2 years $(\beta=$ -6.62 ; $95 \%$ CI: -11.52 to -1.72 ). As described earlier, the association between cord blood lead levels and the cognitive scores was adjusted for potential confounders such as maternal education, birth order, gender of child and prenatal ETS. The adjusted effect of prenatal ETS exposure measured by maternal self-report remained inversely associated with the MDI score, although at a borderline significance level. The mental function of girls was better than in boys, and the impact of maternal education on the mental function of 2- and 3-year-olds remained strongly significant.

Figure 3 presents the predicted effect of prenatal lead exposure in terms of the cognitive function of children measured by MDI score over the follow-up. The predictions were adjusted for the same set of confounders considered in earlier analyses, and were based on the GEE multivariate model. The dose-effect relationship between lead exposure and neurocognitive function is not linear, and suggests that neurocognitive deficits already occur within the level of $5 \mu \mathrm{g} / \mathrm{dl}$ without clear threshold values.
Fig. 2. Scatterplot of MDI scores at $12(\bigcirc)$, $24(\boldsymbol{\nabla})$ and $36(\boldsymbol{\Delta})$ months of follow-up by the cord blood lead level (together with linear fitting and prediction confidence intervals).

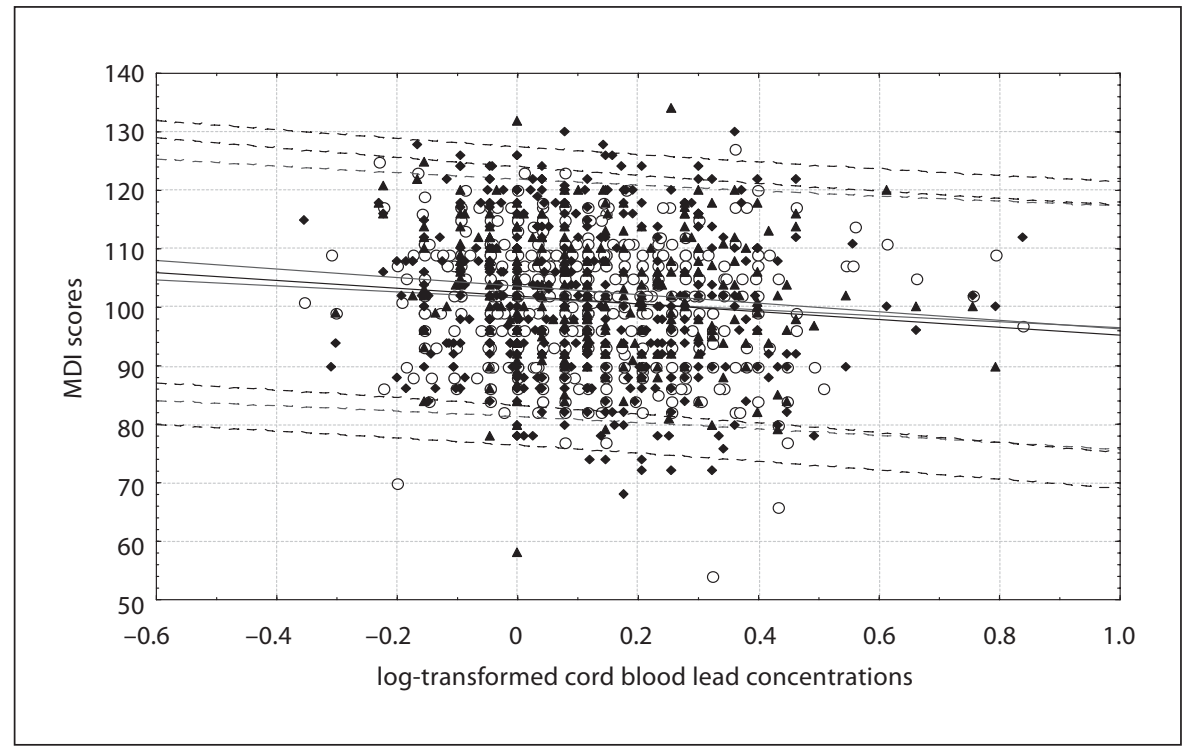


Table 5. Multiple linear regression models testing prenatal lead effects at 12, 24 and 36 months of age (MDI scores adjusted to potential confounders) in the sample of children with blood lead levels $<5 \mu \mathrm{g} / \mathrm{dl}$

\begin{tabular}{|c|c|c|c|c|c|}
\hline & $\beta$ & SE & $\mathrm{t}$ & $\mathrm{p}$ & $95 \% \mathrm{CI}$ \\
\hline \multicolumn{6}{|l|}{ MDI (12 months; $\mathrm{n}=441)$} \\
\hline Maternal education $^{1}$ & 0.699 & 0.375 & 1.87 & 0.063 & -0.037 to 1.436 \\
\hline Birth order & 0.295 & 0.806 & 0.37 & 0.715 & -1.290 to 1.880 \\
\hline Prenatal ETS ${ }^{2}$ & -0.021 & 0.125 & -0.17 & 0.866 & -0.267 to 0.224 \\
\hline Gender of child ${ }^{3}$ & 1.723 & 0.981 & 1.76 & 0.080 & -0.206 to \\
\hline Cord blood lead level ${ }^{4}$ & -5.419 & 2.935 & -1.85 & 0.066 & -11.188 to 0.3495 \\
\hline \multicolumn{6}{|l|}{ MDI (24 months; $\mathrm{n}=415)$} \\
\hline Maternal education ${ }^{1}$ & 1.627 & 0.455 & 3.57 & 0.000 & 0.732 to 2.522 \\
\hline Birth order & -1.829 & 0.962 & -1.90 & 0.058 & -3.721 to 0.063 \\
\hline Prenatal ETS ${ }^{2}$ & -0.313 & 0.150 & -2.08 & 0.038 & -0.609 to -0.018 \\
\hline Gender of child ${ }^{3}$ & 7.221 & 1.187 & 6.08 & 0.000 & 4.887 to 9.555 \\
\hline Cord blood lead level ${ }^{4}$ & -7.653 & 3.577 & -2.14 & 0.033 & -14.684 to -0.623 \\
\hline \multicolumn{6}{|l|}{ MDI (36 months; $\mathrm{n}=384$ ) } \\
\hline Maternal education ${ }^{1}$ & 1.459 & 0.375 & 3.89 & 0.000 & 0.722 to 2.195 \\
\hline Birth order & -2.717 & 0.791 & -3.44 & 0.001 & -4.271 to -1.163 \\
\hline Prenatal ETS 2 & -0.239 & 0.120 & -1.99 & 0.047 & -0.474 to -0.003 \\
\hline Gender of child ${ }^{3}$ & 4.308 & 0.972 & 4.43 & 0.000 & 2.396 to 6.220 \\
\hline Cord blood lead level $^{4}$ & -6.717 & 2.964 & -2.27 & 0.024 & -12.546 to -0.889 \\
\hline
\end{tabular}

Table 6. Cognitive development of children with blood lead levels below 5 $\mu \mathrm{g} / \mathrm{dl}$ over the follow-up in the GEE models (1,240 measurements)

\begin{tabular}{lrlrlr}
\hline MDI (12-36 months) & $\beta$ & SE & z & p & 95\% CI \\
\hline Maternal education $^{1}$ & 1.265 & 0.315 & 4.02 & 0.000 & 0.649 to 1.882 \\
Birth order $_{\text {Prenatal ETS }}^{2}$ & -1.335 & 0.653 & -2.04 & 0.041 & -2.615 to -0.055 \\
Gender of child $^{3}$ & -0.185 & 0.099 & -1.87 & 0.061 & -0.379 to 0.009 \\
Cord blood lead level $^{4}$ & 4.332 & 0.790 & 5.49 & 0.000 & 2.785 to 5.880 \\
\hline
\end{tabular}

\footnotetext{
${ }^{1}$ Primary school only $=0$; medium or high school $=1$; university degree or uncompleted university $=2$.

${ }^{2}$ No exposure $=0 ; 1-10$ cigarettes smoked daily at home $=1,>10$ cigarettes smoked daily at home $=2$.

${ }^{3}$ Boys $=0$, girls $=1 .{ }^{4} \log$ transformed.
}

\section{Discussion}

Although the infants in our study were prenatally exposed to very low lead concentrations, which ranged between 0.44 and $6.90 \mu \mathrm{g} / \mathrm{dl}$, we observed inverse associations between cord blood lead level deficits in cognitive functioning of children already at lead levels below 5.0 $\mu \mathrm{g} / \mathrm{dl}$. The average deficit in cognitive function over the follow-up among children exposed to lead was about 6 points for $1 \log$ unit of cord blood level concentrations (GEE model). The estimated effect of prenatal lead exposure on the cognitive scores of children in the follow-up period was adjusted for potential confounders including maternal education, birth order, gender of child and prenatal ETS exposure. Although the effect was rather modest, an observed trend of cognitive deficit beginning in the second year of life might persist, and even develop, over the coming years. In total, the mental function of 


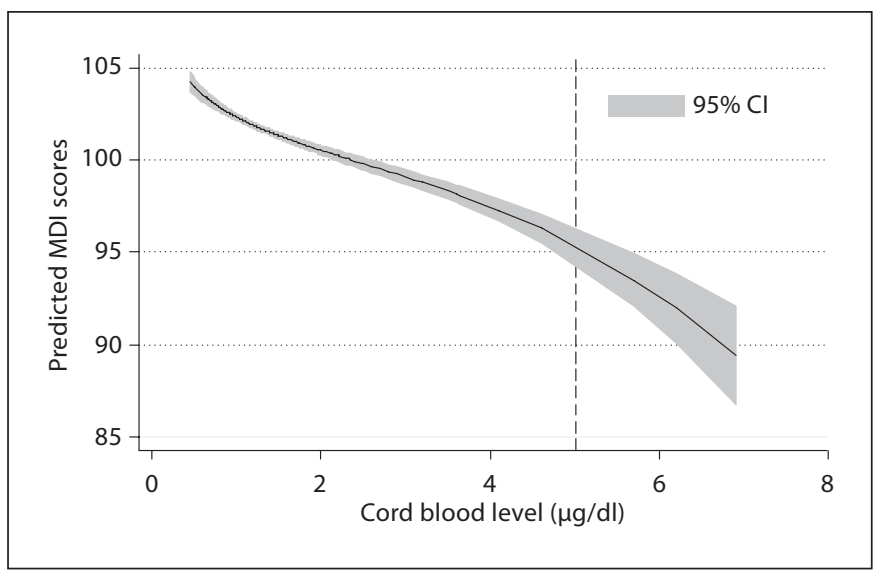

Fig. 3. Predicted effect of prenatal lead exposure on MDI scores.

girls was much better than that of boys, and the impact of maternal education on mental function of 3-year-olds was confirmed.

The results of the presented analysis argue for a reduction in blood lead levels that are below the level of $5 \mu \mathrm{g} / \mathrm{dl}$, and show the need for redefining the primary prevention standards of childhood lead exposure. The current definition of an elevated blood lead level $>10 \mu \mathrm{g} / \mathrm{dl}$ recommended by the Centers for Disease Control and the World Health Organization $[21,22]$ should be verified. We are not able to provide a definite threshold for the adverse effects of lead exposure on cognitive development based on the results of our study, and these should be established in the longer follow-up. In this debate, we have to mention that many of the effects of lead on central nervous system of infants or very young children are difficult to assess with similar accuracy as in older children or adults. Moreover, subclinical neurobehavioral deficits present in very early childhood may be a weak predictor of adult neurocognitive functioning or vocational skills. Thus, the prospective observation of very low exposure to lead and cognitive deficits in children should be extended over a longer period of time.

Low-level lead exposure has been studied widely over the past 2 decades, predominantly in older children [3-8, $10,11,14-16,23-30]$, and the dose-response relationships and possible threshold values for low-level lead toxicity have been under debate. Different methodological approaches used in the studies increase the controversies over the best study designs, choice of adequate marker of lead exposure, most sensitive and valid tools for assessment of neurocognitive development of children, and the choice of the most powerful confounders and modifiers.
Moreover, in previous studies, often higher ranges of blood lead levels (10 to $>30 \mu \mathrm{g} / \mathrm{dl}$ ) were considered. Few studies have recruited samples large enough to detect small effects in the long-term follow-up.

Blood lead levels determined at the time of gestation are probably the most accurate marker of fetal exposure, since toxicokinetic studies in rodents and primates demonstrated that lead readily moves across the placenta. However, it is not clear which blood lead measure is most adequate, i.e. during a specified gestational period, peak blood lead or integrated blood lead measured over gestation. In our study, we used the cord blood concentration of lead, which represents the accumulated dose over the pregnancy period.

The most sensitive endpoints for low-level lead toxicity are not yet known. Some investigators have focused on motor development and others on visual/motor performance based upon the effects of lead observed in occupational settings. In order to capture the early cognitive outcomes of lead exposure in the womb, we chose the Bayley MDI to measure the mental function at follow-up, which is a well standardized tool suitable for assessing intellectual deficits among infants and very young children longitudinally. Not only are the scales well standardized, but they offer an early and fairly comprehensive measure of cognitive functioning. The Bayley taps abilities such as attention, memory and perceptual reasoning, which are thought to be fundamental components of early as well as later intellectual functioning.

The results of the study are consistent with those observed by other authors, i.e. heightened susceptibility of the fetal nervous system to prenatal toxic exposure and that Bayley MDI test scores are a sensitive endpoint for low-level lead toxicity. Several studies have reported similar effects of lead exposures higher than those reported here, either occurring in childhood or prenatally. Needleman and Gatsonis [12], in a meta-analysis of 12 studies of childhood exposures to lead in relation to IQ, found support for the hypothesis that lead impairs children's IQ. The negative partial Spearman correlation coefficient for lead and IQ ranged from -0.27 to -0.003 . However, the limited power of the studies to find an effect (below 0.6 in 7 of 12 studies) and the use of different methods for measuring blood lead concentrations made the studies barely comparable.

Our results are consistent with the data reported by Bellinger et al. [8] who longitudinally analyzed the effect of prenatal and postnatal lead exposure on the early cognitive development of 249 children (BSM-II) examined semiannually over 2 years. On the basis of lead levels in 
umbilical cord blood, children were assigned to 1 of 3 groups: low ( $<3 \mu \mathrm{g} / \mathrm{dl})$, medium $(6-7 \mu \mathrm{g} / \mathrm{dl})$ or high $(>10$ $\mu \mathrm{g} / \mathrm{dl})$. The estimated difference between the adjusted performance of the prenatal lower exposure group $(<3.0$ $\mu \mathrm{g} / \mathrm{dl})$ and higher exposure group $(>10 \mu \mathrm{g} / \mathrm{dl})$ was 4.8 points. Scores were not related to infants' postnatal blood lead levels.

Two recent studies of the effects of low blood level concentrations have been published. In 2000, Lanphear et al. [15] examined data from the NHANES III on 4,853 children between the ages 6 and 16 years. The association between scores on arithmetic and reading skills, achievement scores and blood lead concentration was measured; adjustments were made in the multiple regression analysis for age, race, sex, region of the country, parental marital status and education, poverty level and serum cotinine concentrations. The geometric mean blood lead concentration was $1.9 \mu \mathrm{g} / \mathrm{dl}$ (SE 0.1) and only $9.7 \%$ of children had blood lead concentrations above $5 \mu \mathrm{g} / \mathrm{dl}$. Significant inverse relationships were found for arithmetic and reading tests at blood lead concentrations below $5 \mu \mathrm{g} / \mathrm{dl}$. In 2003, Canfield et al. [16] examined the association between child blood concentrations and Stanford-Binet Intelligence Scale scores in a prospective study of 172 children, aged 6-60 months. The lifetime average blood lead concentration was $7.7 \mu \mathrm{g} / \mathrm{dl}$ at the age of 3 years and 7.4 $\mu \mathrm{g} / \mathrm{dl}$ at the age of 5 years. At 3 years of age, 86 children (57.0\%) had a peak blood lead concentration below $10 \mu \mathrm{g} /$ $\mathrm{dl}$, as did $86(55.8 \%)$ at the age of 5 years (71 of these children had such a concentration at both ages, and the remaining 30 had this concentration at either 3 or 5 years). Blood lead concentrations, even those below $10 \mu \mathrm{g} / \mathrm{dl}$, were inversely associated with children's IQ scores at 3 and 5 years of age, and associated declines in IQ are greater at these concentrations than at higher concentrations.

A very recent cohort study in Mexico [31] compared cognitive function related to prenatal and postnatal lead exposure in the sample of 175 children from pregnancy through 10 years of age. The geometric mean of cord blood lead was $8.0 \mu \mathrm{g} / \mathrm{dl}$ (range $1-33 \mu \mathrm{g} / \mathrm{dl}$ ), from 1 through 5 years it was $9.8 \mu \mathrm{g} / \mathrm{dl}(2.8-36.4 \mu \mathrm{g} / \mathrm{dl})$, and from 3 through 10 years of age it was $6.2(2.2-18.6 \mu \mathrm{g} / \mathrm{dl})$. The authors found that lead exposure around 28 weeks' gestation was critical for later childhood intellectual development with lasting or permanent effects. No threshold values were found and the strongest lead effects on IQ were observed within the first few micrograms of blood lead.

Interestingly, in the course of our cohort study, we have been able to show not only the adverse effect of lead exposure, but also impact of prenatal ETS exposure on the cog- nitive development over the 3-year follow-up. The adverse impact of fetal exposure to ETS over the first years of life may be due to mechanisms exerted by the many ETS constituents. They may alter receptor-mediated cell signaling in the brain [32], induction of P450 enzymes [33] or cause DNA damage by activating apoptotic pathways [34, 35]. Our observation is in agreement with the results of Rauh et al. [36] who reported significant deficits in cognitive test scores among 2-year-olds who were exposed prenatally to ETS, after controlling for ETS exposure during the first 2 postnatal years. Since indoor polychlorinated biphenyls (PAH) result from ETS, the ETS-related cognitive deficit could be attributable in part to PAH. The earlier study of Perera et al. [37] showed that PAH at levels encountered in the urban community may adversely affect cognitive development of preschool children.

Our study has several potential limitations. First, the study sample may not be representative of the female urban population in the country because enrollment covered only pregnant nonsmoking women with singleton pregnancies between the ages of 18 and 35 years who were free from chronic diseases, such as diabetes and hypertension. These criteria eliminated infants at greater risk of neurocognitive disorders from the study because of maternal chronic diseases or active smoking. Moreover, we were not able to control for postnatal lead exposure during the follow-up. Although estimated effects of lead exposure on cognitive skills were adjusted for numerous potential confounders, we did not consider home environment parameters and maternal intelligence in the study, which may have biased the detrimental effects of prenatal lead exposure. In fact, maternal education level considered in our study might be treated as a possible surrogate for maternal intelligence and home environment.

Summing up, the data from our study demonstrate that a neurotoxic impact of very low levels of prenatal lead exposure may occur in infants and very young children, and suggest a guideline for a cord blood lead critical value below $5 \mu \mathrm{g} / \mathrm{dl}$. To determine whether the cognitive deficit documented in this study persists in older ages, we plan to extend the follow-up over the next few years. This will enable us to assess the dynamics of mental development of children in relation to lead exposure.

\section{Acknowledgments}

This is part of an ongoing comparative longitudinal investigation on the health impact of prenatal exposure to outdoor/indoor air pollution in infants and children being conducted in New York 
City and Krakow. The study received funding from an RO1 grant entitled, 'Vulnerability of the Fetus/Infant to PAH, PM2.5 and ETS' (5 RO1 ES10165 NIEHS; 02/01/00-01/31/04) and The Gladys T. and Roland Harriman Foundation. Principal investigator: F.P.P.
Thanks are due to Robert Jones, $\mathrm{PhD}$, and Kathleen Caldwell, $\mathrm{PhD}$, of the Centers for Disease Control Environmental Health Laboratory for performing measurements of lead levels in blood samples.

\section{References}

1 Freedman R, Olson L, Hoffer BJ: Toxic effects of lead on neuronal development and function. Environ Health Perspect 1990;89: 27-33.

-2 Juberg DR, Kleiman CF, Simona C, Kwon SC: Position paper of the American Council on Science and Health: lead and human health. Ecotoxicol Environ Saf 1997;38:162-180.

3 Dietrich KN, Krafft KM, Bier M, Succop PA, Berger O, Bornschein RL: Early effects of fetal lead exposure: neurobehavioral findings at 6 months. Int J Biosocial Res 1986;8:151-168.

-4 Dietrich KN, Krafft KM, Bornschein RL, Hammond PB, Berger O, Succop PA, Brier BA: Low-level fetal lead exposure effect on neurobehavioral development in early infancy. Pediatrics 1987;80:721-730.

5 Dietrich KN, Berger OG, Succop PA: Lead exposure and the motor developmental status of urban six-year-old children in the Cincinnati Prospective Study. Pediatrics 1993; 91:301-307.

-6 Fahim MS, Fahim Z, Hall DG: Effects of subtoxic lead levels on pregnant women in the State of Missouri. Res Commun Chem Pathol Pharmacol 1976;13:309-331.

-7 Bellinger D, Leviton A, Waternaux C, Needleman H, Rabinowitz M: Longitudinal analyses of prenatal and postnatal lead exposure and early cognitive development. $\mathrm{N}$ Engl J Med 1987;316:1037-1043.

-8 Bellinger DC, Stiles KM, Needleman HL: Low-level lead exposure, intelligence and academic achievement: a long-term follow-up study. Pediatrics 1992;90:855-861.

$\checkmark 9$ Goyer R.A. Lead toxicity: current concerns. Environ Health Perspect 1993;100:177-187.

10 Emory E, Ansari Z, Pattillo R, Archibold E, Chevalier J: Maternal blood lead effects on infant intelligence at age 7 months. Am J Obstet Gynecol 2003;188:S26-S32.

-11 Emory E, Pattillo R, Archibold E, Bayorh M, Sung F: Neurobehavioral effects of low-level lead exposure in human neonates. Am J Obstet Gynecol 1999;181:S2-S11.

-12 Needleman HL, Gatsonis CA: Low-level lead exposure and the IQ of children: a metaanalysis of modern studies. JAMA 1990;263: 673-678.

13 Pocock SJ, Smith M, Baghurst P: Environmental lead and children's intelligence: systematic review of the epidemiological evidence. BMJ 1994;309:1189-1197.

-14 Wigg NR, Vimpani GV, McMichael AJ, Baghurst PA, Robertson EF, Roberts RJ: Port Pirie Cohort study: childhood blood lead and neuropsychological development at age two years. J Epidemiol Community Health 1998; 42:213-219.
5 Lanphear BP, Dietrich K, Auinger P, Cox C: Cognitive deficits associated with blood lead concentrations $<10 \mu \mathrm{g} / \mathrm{dl}$ in US children and adolescents. Public Health Rep 2000;115: 521-529.

16 Canfield RL, Henderson CR, Cory-Slechta DA, Cox C, Jusko TA, Lanphear BP: Intellectual impairment in children with blood lead concentrations below 10 micrograms per deciliter. New Engl J Med 2003;348:15171526.

17 Jedrychowski W, Whyatt RM, Camman DE, Bawle UV, Peki K, Spengler J, Dumyahn TS, Penar A, Perera FP: Effect of prenatal PAH exposure on birth outcomes and neurocognitive development in a cohort of newborns in Poland: study design and preliminary ambient data. Int J Occup Med Environ Health 2003; 16:21-29.

18 CDC: Whole Blood Lead, Cadmium and Mercury Determined Using Inductively Coupled Plasma Mass Spectrometry, DLS method code: 2003-01/OD. CLIA methods. Atlanta, Centers for Disease Control and Prevention, 2003.

19 Bayley N: Bayley Scales of Infant Development, ed 2 (manual). San Antonio, Psychological Corporation, 1993.

20 Hardin JW, Hilbe JM. Generalized Linear Models and Extensions, ed 2. College Station, Stata, 2007.

21 Centers for Disease Control (US): Preventing Lead Poisoning in Young Children: A Statement by The Centers for Disease Control. Atlanta, Department of Health and Human Services (US), 1991.

22 World Health Organization International Programme on Chemical Safety: Environmental Health Criteria 165-Inorganic Lead. Geneva, WHO, 1995.

-23 Ernhart CB, Wolf AW, Kennard MJ, Erhard P, Filipovich HF, Sokol RJ: Intrauterine exposure to low levels of lead: the status of the neonate. Arch Environ Health 1986;41:287-291.

24 Rothenberg SJ, Schnaas L, Cansino-Ortiz S, Perroni-Hernández E, de la Torre P, NeriMéndez C, Ortega P, Hidalgo-Loperena H, Svendsgaard D: Neurobehavioral deficits after low level lead exposure in neonates: the Mexico City pilot study. Neurotoxicol Teratol 1989;11:85-93.

25 David O, Clark J, Voeller K: Lead and hyperactivity. Lancet 1972;2:900-903.
26 David OJ, Hoffman SP, Sverd J, Clark J: Lead and hyperactivity: lead levels among hyperactive children. J Abnorm Child Psychol 1977;5:405-416.

27 Gittelman R, Eskenazi B: Lead and hyperactivity revisited: an investigation of nondisadvantaged children. Arch Gen Psychiatry 1983;40:827-833.

28 Fergusson DM, Horwood LJ, Lynskey MT: Early dentine lead levels and subsequent cognitive and behavioural development. J Child Psychol Psychiatry 1993;34:215-227.

29 Needleman HL, Gunnoe C, Leviton A, Reed $\mathrm{R}$, Peresie H, Maher C, Barrett P: Deficits in psychologic and classroom performance of children with elevated dentine lead levels. $\mathrm{N}$ Engl J Med 1979;300:689-695.

30 Ruff HA, Markowitz ME, Bijur PE, Rosen JF: Relationship among blood lead levels, iron deficiency, and cognitive development in two-year-old children. Environ Health Perspect 1996;104:180-185.

31 Shnass L, Rothenberg SJ, Flores MF, Martinez S, Hermandez C, Osorio E, Velasco SR, Perroni E: Reduced intellectual development in children with prenatal lead exposure. Environ Health Perspect 2006;114:791-797.

32 Slotkin A: Fetal nicotine or cocaine exposure: which one is worse? J Pharmacol Exp Ther 1998;285:931-945.

33 Manchester DK, Gordon SK, Golas CL, Roberts EA, Okey AB: Ah receptor in human placenta: stabilization by molybdate and characterization of binding of 2,3,7,8-tetrachlorodibenzo-pdioxin, 3-methylcholanthrene, and benzo(a)pyrene. Cancer Res 1987;47:4861-4868.

- 34 Nicol CJ, Harrison ML, Laposa RR, Gimelshtein IL, Wells PG: A teratologic suppressor role for p53 in benzo[a]pyrene-treated transgenic p53-deficient mice. Nat Genet 1995;10: 181-187.

35 Wood KA, Youle RJ: The role of free radicals and p53 in neuron apoptosis in vivo. J Neurosci 1995; 15:5851-5857.

36 Rauh VA, Whyatt RM, Garfinkel R, Andrews H, Hoepner L, Reyes A, Diaz D, Camann D, Perera FP: Developmental effects of exposure to environmental tobacco smoke and material hardship among inner-city children. J Neurotoxicol Teratol 2004;26:373-385.

37 Perera FP, Rauh V, Whyatt RM, Tsai WY, Tang D, Diaz D, Hoepner L, Barr DB, Tu YH, Camann DE, Kinney PL: Effect of prenatal exposure to airborne polycyclic aromatic hydrocarbons on neurodevelopment in the first 3 years of life among inner-city children. Environ Health Perspect 2006;114: 1287-1292. 